\title{
Seed coating with biological agents to improve the quality of rice seeds contaminated with blast pathogens and increase seedling growth
}

\author{
TANTRI PALUPI", FADJAR RIYANTO \\ Faculty of Agriculture, Universitas Tanjungpura. Jl. Prof. Hadari Nawawi, Pontianak 78124, West Kalimantan, Indonesia. \\ Tel.: +62-561-785342, 583865, Fax.: +62-561-765342, ^email: tantripalupi@yahoo.com \\ Manuscript received: 18 November 2019. Revision accepted: 21 January 2020.
}

\begin{abstract}
Palupi T, Riyanto F. 2020. Seed coating with biological agents to improve the quality of rice seeds contaminated with blast pathogens and increase seedling growth. Biodiversitas 21: 683-688. The aim of this research were (1) to evaluate the compatibility of five biological agents (SP21, SP31, RP21, TP12, and TP11), (2) to evaluate the physical and physiological quality of rice seeds contaminated with Pyricularia grisea after being treated with seed coating enriched with biological agents, (3) to evaluate the effectiveness of seed coating on the incidence of blast disease and seedling growth. The first experiment tested the compatibility of five bacterial antagonists on the PSA plates. There were eight treatments in the second experiment namely seed coating enriched with SP21+SP31; SP21+RP21; SP21+TP12; SP31+RP21; RP21+TP11; fungicides; positive control (rice seeds contaminated with blast), and negative control (healthy seeds), and seven treatments in the third experiment which were the same as in experiment 2 without negative control. Parameters observed in the second experiment were: seed germination, vigor index, and growth rate, while parameters observed in the $3^{\text {rd }}$ experiment were the incidence rate of blast disease and plant height. The results of experiment 1 showed that isolates SP21+SP3, SP21+RP21, SP21+TP12, SP31+RP21, and RP21+TP11 had good growth compatibility without antagonism, and they can be used as biocontrol agents. Results of experiment 2 showed that seed coating enriched with SP21+SP31 isolates has the potential to improve the physical and physiological quality of the seeds. Results of experiment 3 showed that seed coating enriched with RP21+TP11 had no incidence of blast disease up to 4 weeks after planting.
\end{abstract}

Keywords: coated rice seeds, seed quality, blast disease, seedling growth, Pyricularia grisea.

\section{INTRODUCTION}

In recent years, the productivity of rice, especially lowland rice, has declined. Since 2015 the productivity of lowland rice has decreased from $5.51 \mathrm{t} \mathrm{ha}^{-1}$ to $5.40 \mathrm{t} \mathrm{ha}^{-1}$ in 2016 and $5.30 \mathrm{t} \mathrm{ha}^{-1}$ in 2017 (BPS 2017). This value is much lower when compared to its potential, which is 7-8 t $\mathrm{ha}^{-1}$ (Agriculture Department 2006). The use of low quality and disease-infected seeds are the main cause of the current low productivity of rice.

Blast is one of the important diseases in rice plantations in Indonesia caused by the fungus Pyricularia grisea. Blast disease is starting to become an important obstacle for the cultivation of lowland rice, especially when the blast is attacking superior varieties that are susceptible to blast. $P$. grisea fungus can infect rice plants in all growth phases and can reduce very large yields. A study by Suganda et al., (2016) showed that the intensity of blast disease in rice varieties of Ciherang in endemic areas was $55.60 \%$ for leaf blasts, and $37.75 \%$ for panicle neck blasts, with the potential loss of yield by blast disease is 3.65 tons/ha or equivalent to $61 \%$ when compared to the average production of Ciherang variety. Amir and Kardin (1991) reported that the rate of yield loss due to neck black attacks could reach 90\%, and cause rice yield losses to reach 50$90 \%$ in susceptible varieties. Rice planting that was attacked by the blast with an intensity above $20 \%$ resulted in P. grisea infected seeds reaching $22.5 \%$ (Sudir 2012).
Disease, environmental stress, and nutrient deficiencies, inadequate fertilizer, and poor quality seeds are obstacles in rice cultivation, which causes low productivity, so it requires proper treatments. The disease can spread quickly and widely through seeds (seed-borne diseases) in rice cultivation, therefore to get pathogens free plants, prevention is needed, among others, through seed treatment.

Treatment of seeds enriched with biological agents done by immersing the seeds in a biological microbial suspension, but this method requires the ability in determining the appropriate concentration of solution and solvent conditions. Another seed treatment by using biological agents can be done through seed coating. The seeds are coated with a certain coating solution that carries biological agents through immersion, dipping, or spraying. After that, the seeds are dried to certain water content, followed by storing the seeds. This method is considered better because the seeds can be planted without giving additional treatment. Seed coating using several biological microbes have been reported being effective in controlling Xanthomonas oryzae pv. oryzae (Xoo) carried by rice seeds, both on the seed surface and inside the seeds (Palupi, et al. 2013). Coated seeds that carry biological agents are expected to protect seeds and plants as early as possible from disease attacks.

This study aims to evaluate the compatibility of five biological agents, to evaluate the formula of seed coating enriched with biological agents to improve the physical and 
physiological quality of the rice seeds contaminated with $P$. grisea, and to evaluate the effectiveness of seed coatings on the incidence rate of blast disease and rice seedling growth in the screen house.

\section{MATERIALS AND METHODS}

This research was conducted from March to November 2018, at the Laboratory of Plant Pests and Experimental Gardens at the Faculty of Agriculture, Tanjungpura University, Pontianak. The seeds used in this research were rice seeds contaminated with $P$. grisea. The coating formula used in this study was according to Palupi's (2012) with modification to carry biological agents of the bacterial phyllosphere of leaf isolates (SP21, SP31, RP21, TP12, and TP11) (Yaskur 2018). Systemic fungicides with active compounds of Propikanazol and Trichlazazole are used as a comparison. The coating technique uses the manual method.

The research consisted of three activities. In the first experiment, five bacterial antagonists, i.e., isolates SP21, SP31, RP21, TP12, and TP11, were tested for their compatibility with each other on PSA plates. The second experiment used a completely randomized design with eight different seed coating treatments, which are seed coating enriched with isolates: (A) SP21+SP31; (B) SP21+RP21; (C) SP21+TP12; (D) SP31+RP21; (E) RP21+TP11; (F) fungicides; (G) positive control (rice seeds contaminated with blast), and $(\mathrm{H})$ negative control (healthy seeds). The third experiment used a completely randomized design with a single factor (seed coating) consisting of seven treatments, namely: seed coating enriched with (A) SP21+SP31; (B) SP21+RP21; (C) SP21+TP12; (D) SP31+RP21; (E) RP21+TP11; (F) fungicides; and $(\mathrm{G})$ positive control (rice seeds contaminated with blast).

\section{Procedures}

Bacterial suspension of isolates SP21, SP31, RP21, TP12, and TP11, were prepared to match the turbidity of 0.5 McFarland, having approximately the cell density of 15

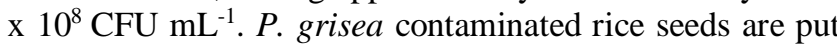
into bottles that have been filled with a coating formula, and then the bottles were shaken until the seeds are evenly mixed with the coating formulation. After the seeds have fused with the coating formula, an aerial dryer is carried out using a fan, where the seeds are stored in the Petri dish and allowed to stand until the seeds absorb the formula. When the seeds have dried, the seeds are stored in plastic bags using tweezers.

\section{Examination of compatibility}

Compatibility evaluation using harmony examination among biological agents that not interfere with one another.

\section{Evaluation of the physical and physiological quality of seeds}

Examination of seed physiological quality conducted on paper established in a plastic method in eco-germinator. This study consisted of 8 treatments with four replicates.
Each replicates consisted of two samples, in which one sample for observing the vigor index and germination, another sample for observing the growth rate. Each sample consisted of 50 seeds. The parameters observed for seed physiological quality were vigor index $(\%)$, germination percentage (\%), and growth rate (\%/etmal). Vigor index was calculated by the formula according to Sadjad et al. (1999) as follows:

Seed vigor Index $=$ Total of normal shoots at the five-day germination $\times 100 \%$ Total of seeds

Germination percentage (\%) was calculated by the formula of Sadjad et al. (1999) as follows:

\section{Germination Percentage $=$ Total of normal shoots at the seven days germination $\times 100 \%$} Total of seeds

Growth rate (\%/etmal) was calculated by the formula of Sadjad et al. (1999) as follows:

Total addition of normal shoot per day (interval 24 hours) /number of shoots on the last day of observation ( 7 days after seedling)

\section{The incidence rate of blast disease and plant height}

Observations were made at the incidence rate of blast disease and plant height at 2, 3, and 4 weeks after planting. Observations on blast disease were carried out based on IRRI (Table 1). The scale value is $\mathrm{n}$ converted to percent using the disease intensity (DI) formula as follows:

(DI) $=\mathrm{S}($ ni $\times \mathrm{I} \times 1 / \mathrm{N} \times \mathrm{V}) \times 100 \%$.

Where:

DI : disease intensity

$\mathrm{Ni}$ : number of samples with scale $\mathrm{i}$,

I : disease severity scale (0-9),

$\mathrm{N}$ : number of samples observed,

$\mathrm{V}$ : highest disease scale.

\section{Data analysis}

Data were analyzed using Analysis of Variance (ANOVA) at a 95\% confidence level, significant differences between two treatments were analyzed with Duncan's Multiple Range Test (DMRT) (Gomez and Gomez 1995) using Statistical Analysis System (SAS) version 9.1.

\section{RESULTS AND DISCUSSION}

\section{Compatibility of biological agents}

In-vitro compatibility tests on five biological agents, i.e.; 1 (SP21), isolate 2 (SP31), isolate 3 (RP21), isolate 4 (TP12), and isolate 5 (TP11) were presented in Figure 1. The results of the compatibility test showed that SP21+SP31 isolates, SP21+RP21 isolates, SP21+TP12 isolates, SP31+RP21 isolates, and RP21+TP11 had good growth compatibility without antagonism (not interfere with each other) so that it can be used to enrich the coating of rice seeds in the next experiment. 


\section{Physical and physiological quality of the seeds}

The seed quality coated with biological agents presented in Table 2, while rice seeds that have been coated with biological agents were shown in Figure 2. The water content of coated rice seeds increased to $12.24 \%$, while the water content of non-coated rice seeds (control) was $11 \%$.

Table 2 showed that the coating treatment enriched with SP21+SP31 isolates was the best treatment based on the vigor index and seed growth rate, which was significantly different compared to positive control treatments (pathogen-contaminated seeds) but not significantly different compared to negative controls (seeds were not contaminated with pathogens). Vigor index and growth rate were important parameters that indicated the ability of seeds to grow in the sub-optimum conditions of the field.
The incidence rate of blast disease and plant height

Observations on the incidence of blast disease and plant height at 2, 3, and 4 weeks after planting presented in Tables 3 and 4 .

Table 3 showed that the incidence of blast disease did not appear at 2 and $3 \mathrm{WAP}$, however, the symptoms of blast disease appeared at 4 WAP. The highest incidence of blast disease $(26,83 \%)$ was observed in the seed coating treatment enriched with SP21+SP31 isolates that were not significantly different from the positive control treatment, fungicide treatment, and other treatments, except seed coating treatment enriched with RP21+TP11 isolates $(0.0 \%)$. However, seed coating treatment enriched with RP21+TP11 isolates did not show a different effect with positive control treatments. Observations on seedling height were presented in Table 4.

Table 1. Scores of rice leaf blast disease (IRRI 1996)

\begin{tabular}{lll}
\hline \multicolumn{1}{c}{ Symptoms score } & \multicolumn{1}{c}{ Character } & \multicolumn{1}{c}{ Notations } \\
\hline 0 & $\mathrm{R}$ & no symptoms of blast disease \\
1 & $\mathrm{R}$ & there are spots as large as the tip of the needle (LAA = 0.5\%) \\
2 & $\mathrm{R}$ & patches larger than the tip of the needle (LAA =1\%) \\
3 & $\mathrm{R}$ & grayish patches, roundish rather oval, 1-2 mm long with brown edges (LAA=2\%) \\
4 & SR & Specific blast blots, 1-2 mm long. LAA <5\%. \\
5 & SR & Specific blast blots, LAA 5-10\% \\
6 & $\mathrm{~S}$ & Specific blast blots, LAA 11-25\% \\
7 & $\mathrm{~S}$ & Specific blast blots, LAA 26-50\% \\
8 & $\mathrm{~S}$ & Specific blast blots, LAA 51-75\% \\
9 & $\mathrm{~S}$ & Specific blast blots, LAA 76-100\% \\
\hline
\end{tabular}

Note: R: Resistant SR: Somewhat Resistant S: susceptible LAA: Leaf area attacked

Table 2. Vigor Index, Germination, and Growth Rate of coated rice seeds enriched with biological agents

\begin{tabular}{lccc}
\hline \multicolumn{1}{c}{ Treatment } & Vigor index (\%) & Germination (\%) & Growth rate (\%) \\
\hline Coating formula+ isolates SP21+SP31 & $62.00 \mathrm{ab}$ & $92.00 \mathrm{~b}$ & $19.14 \mathrm{ab}$ \\
Coating formula+ isolates SP21+RP21 & $48.67 \mathrm{bc}$ & $94.67 \mathrm{a}$ & $19.32 \mathrm{a}$ \\
Coating formula+ isolates SP21+TP12 & $57.33 \mathrm{~b}$ & $91.33 \mathrm{ab}$ & $17.16 \mathrm{bcd}$ \\
Coating formula+ isolates SP31+RP21 & $52.00 \mathrm{bc}$ & $91.33 \mathrm{ab}$ & $18.17 \mathrm{abc}$ \\
Coating formula+ isolates RP21+TP11 & $47.33 \mathrm{bc}$ & $88.00 \mathrm{~b}$ & $17.49 \mathrm{abcd}$ \\
Fungicide (without coating formula) & $42.00 \mathrm{bc}$ & $73.33 \mathrm{c}$ & $15.57 \mathrm{~d}$ \\
Positive control (contaminated seed) & $33.33 \mathrm{c}$ & $90.00 \mathrm{ab}$ & $16.28 \mathrm{~cd}$ \\
Negative control (uncontaminated seeds) & $80.00 \mathrm{a}$ & $92.67 \mathrm{ab}$ & $18.44 \mathrm{ab}$ \\
\hline
\end{tabular}

Note: numbers followed by the same letter in the same column showed no significant difference in DMRT $\alpha=5 \%$.

Table 3. The incidence of blast disease in rice seedlings coated with biological agents at 2, 3, and 4 weeks after planting (WAP)

\begin{tabular}{|c|c|c|c|}
\hline \multirow{2}{*}{ Treatments } & \multicolumn{3}{|c|}{ The intensity of blast disease (\%) } \\
\hline & 2 WAP & 3 WAP & 4 WAP \\
\hline Coating formula + isolate SP21+SP31 & 0 & 0 & $26.83 \mathrm{a}$ \\
\hline Coating formula + isolate SP21+RP21 & 0 & 0 & $22.33 \mathrm{ab}$ \\
\hline Coating formula + isolate SP21+TP12 & 0 & 0 & $8.23 \mathrm{ab}$ \\
\hline Coating formula + isolate SP31+RP21 & 0 & 0 & $7.65 \mathrm{ab}$ \\
\hline Coating formula + isolate RP21+TP11 & 0 & 0 & $0.00 \mathrm{~b}$ \\
\hline Fungicide (without coating formula) & 0 & 0 & $26.78 \mathrm{a}$ \\
\hline Positive control (the seeds contaminated with $P$. grisea) & 0 & 0 & $15.30 \mathrm{ab}$ \\
\hline
\end{tabular}

Note: WAP: the week after planting. Same letters in the same column are not significantly different at $p \geq 0.05$ according to DMRT 
Table 4. Height of rice seedlings coated with biological agents at 2, 3, and 4 weeks after planting (WAP)

\begin{tabular}{lcc}
\hline \multirow{2}{*}{ Treatments } & \multicolumn{2}{c}{ Plant height (cm) } \\
\cline { 2 - 3 } & 2 WAP & 4 WAP \\
\hline Coating formula + isolate SP21+SP31 & 16.87 & $22.94 \mathrm{a}$ \\
Coating formula + isolate SP21+RP21 & 16.29 & $24.77 \mathrm{a}$ \\
Coating formula + isolate SP21+TP12 & 16.00 & $27.62 \mathrm{ab}$ \\
Coating formula + isolate SP31+RP21 & 17.13 & $29.04 \mathrm{a}$ \\
Coating formula + isolate RP21+TP11 & 13.88 & $28.65 \mathrm{a}$ \\
Fungicide (without coating formula) & 15.32 & $21.88 \mathrm{ab}$ \\
Positive control (the seeds contaminated with $P$. grisea) & 14.72 & $22.14 \mathrm{ab}$ \\
\hline
\end{tabular}

Note: Same letters in column are not significantly different at $\mathrm{p}=0.05$ according to DMRT

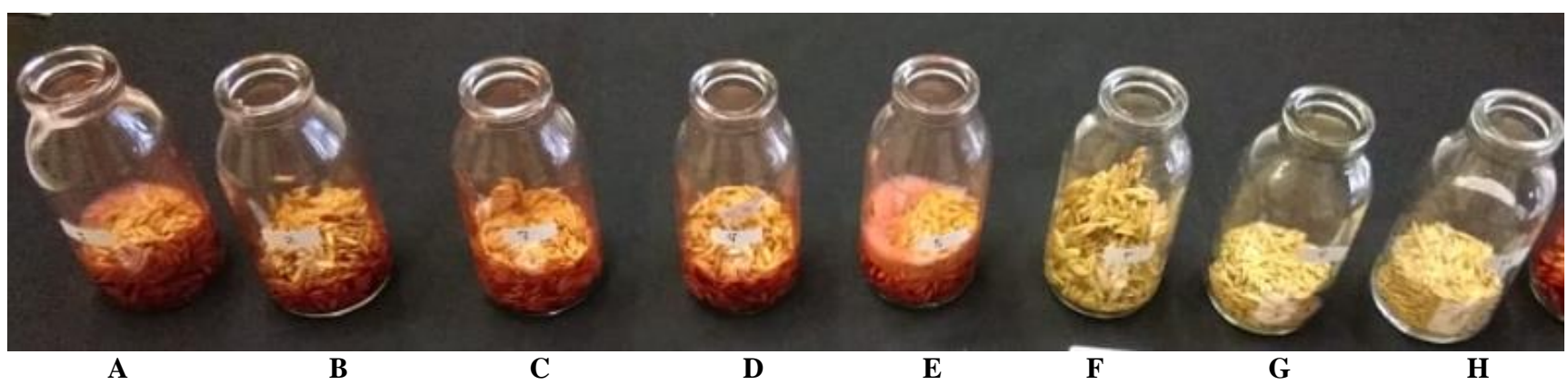

Figure 2. Coatings of rice seeds enriched with biological agents. Coating formula enriched with: A. Isolates SP21+SP31; B. Isolates SP21+RP21; C. Isolates SP21+TP12; D. Isolates SP31+RP21; E. Isolates RP21+TP11; F. Fungicide; G. Positive control (rice seeds contaminated with blast); and H. Negative control (healthy seeds)

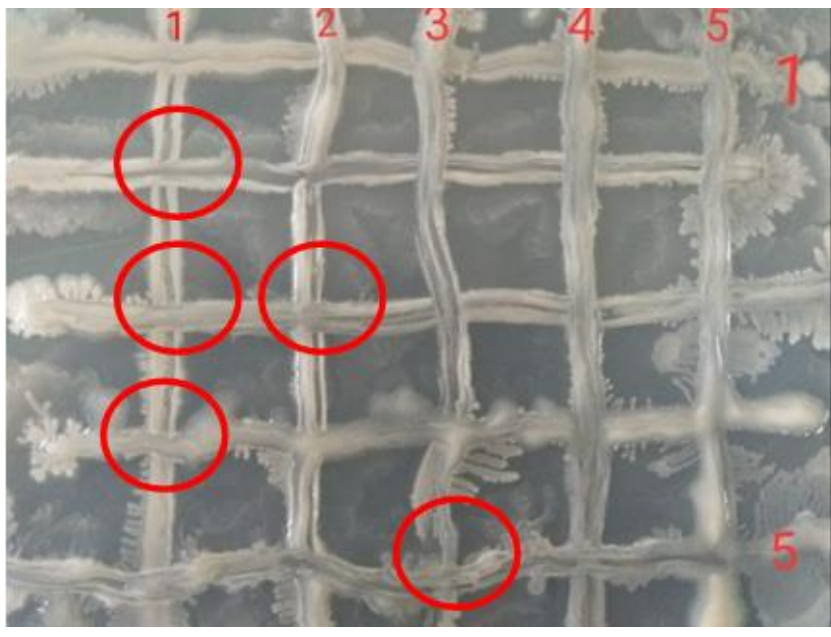

Figure 1. In-vitro compatibility between two biological agents: $\mathrm{SP} 21+\mathrm{SP} 31$ isolates, SP21+RP21 isolates, SP21+TP12 isolates, SP31+RP21 isolates, and RP21+TP11 isolates. The red circle showed no antagonism of two isolates of biological agents.

Table 4 shows that plant height at 2 WAP at all treatments was not significantly different, however, the height of rice seedlings coated with biological agents at 3 WAP was higher significantly than positive control treatments (the seeds contaminated with $P$. grisea). Treatments of seed coating enriched with biological agents
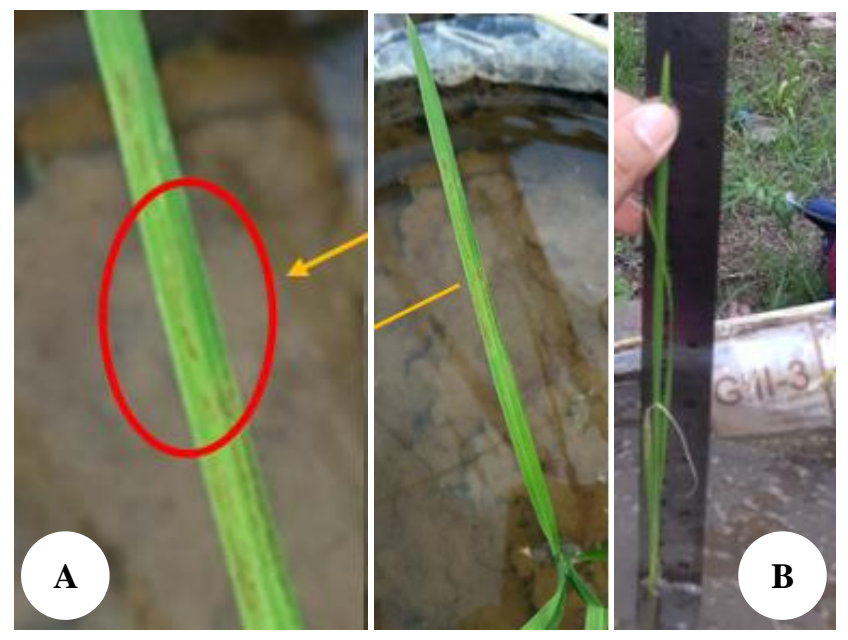

Figure 3. (A) Spots on rice leaves indicated BLAST disease, (B) measuring the height of rice seedling.

of SP21+SP31, SP21+RP21, SP21+TP12, and SP31+RP21 was resulting in significantly higher seedling height, ranging from 22.94 to $24.77 \mathrm{~cm}$ than positive control treatment $(19,53 \mathrm{~cm})$, but not significantly different from fungicide treatment and seed coating enriched with isolates $\mathrm{RP} 21+\mathrm{TP} 11$. At $4 \mathrm{WAP}$, the height of rice seedlings of the 
coating treatment enriched with biological agents of $\mathrm{SP} 21+\mathrm{RP} 21, \mathrm{SP} 21+\mathrm{TP} 12$, and SP31+RP21 ranged from 28.66 to $29.04 \mathrm{~cm}$ which was significantly different from positive control $(24.97 \mathrm{~cm})$, but not significantly different from fungicide treatment, and seed coating enriched with isolates RP21+TP11, and SP21+SP31.

\section{Discussion}

The rice seeds used in this study were seeds from rice plants that were attacked by blast disease. Blast disease is one of the biotic stresses, in which pathogens can be carried out by the seeds either on the surface or inside the seeds. Infected seeds can be observed macroscopically (Sutopo 2002). Pathogens can be carried out from plant residues, soil grains, sand or in the form of pathogenspecific structures (Sinaga 2003). The water content of coated rice seeds increased to $12.24 \%$, while the water content of uncoated rice seeds (control) was $11 \%$. According to Ilyas (2003), seed coating uses less material so that the shape of the original seed is still visible, and a slight increase in seed weight.

SP21 and SP31 isolates were bacteria isolated from rice leaf filaments, and they were very potential to inhibit the growth of $P$. grisea in dual culture antagonists in vitro. SP21 isolate has inhibition of $81.18 \%$ while SP31 isolate has inhibition of $78.33 \%$ against P. oryzae (Yaskur 2018). Antagonistic microbe categorized as having inhibitory activity if the percentage of inhibition was $\geq 60 \%$. The antagonistic microbe that has only $30 \%$ inhibition has classified as having a minimal inhibitory effect (Otter et al. 2004).

SP21 and SP31 isolates were bacteria that able to produce $43.90 \%$, and $32.60 \%$ chitinase, respectively (Yaskur 2018). Bacteria isolates that produce chitinase enzymes can destroy the cell wall of pathogenic fungi. Chitinase hydrolyzes chitin, which is a component of pathogenic fungal cell walls when contact occurs between bacterial isolates and pathogenic fungi. Therefore, chitinase is known as an antifungal protein (Sucipto 2016).

Treatment of seed coating enriched with isolate RP21+TP11 showed no symptoms of blast disease up to 4 WAP. It is indicated that bacteria isolates RP21+TP11 were able to suppress the growth of pathogenic fungi that causes blast disease in contaminated rice seeds. Isolate RP21 was isolated from a healthy plant phyllosphere in the environment of the low incidence of blast disease. Isolate RP21 has a chitinase index of $30.28 \%$ and was able to inhibit the growth of $P$. grisea in dual culture antagonists in vitro by $72.72 \%$. Isolate TP11 was isolated from healthy plant filaments in high blast occurrence environments and was able to inhibit the growth of $P$. grisea by $76.12 \%$, with a chitinase index of $48.78 \%$. (Yaskur 2018). Treatment of seed coating enriched with isolates RP21 + TP11 when compared with positive control treatments did not cause differences in influence, but there was a potential for suppression of disease attacks, so application repetition was needed in the next growth phase. A study by Nortin (2019) showed that seed coating with biological agents of TP11 isolates may inhibit the development of blast disease more effective, so it can suppress the growth of blast disease caused by $P$. grisea in rice plants in the field

Blast disease control is more effective if done as early as possible, such as starting from seed treatment before planting because $P$. grisea can transmit through seeds. Therefore, it is necessary to treat the seeds using biological agents that can be done by the seed coating method. Seed coating is more effective in reducing the level of $P$. grisea infection in seeds compared to the soaking method (Sudir et al. 2014).

In conclusion, the results of this research showed that: (i) combination of isolates $\mathrm{SP} 21+\mathrm{SP} 31 ; \mathrm{SP} 21+\mathrm{RP} 21$; SP21+TP12; SP31+RP21; and RP21+TP11, had good growth compatibility without antagonism, while the mixture in between showed resistance to each other. Therefore, the combination of SP21+SP31, SP21+RP21; SP21+TP12; SP31+RP21; and RP21+TP11 can be used as biocontrol agents. (ii) The treatment of seed coating enriched with SP21+SP31 isolates has the potential to improve the physical and physiological quality of the seed, based on the vigor index value and seed growth rate with a more attractive physical appearance of the seed. (iii) The treatment of seed coating enriched with isolate RP21+TP11 can reduce the incidence of blast disease to $0 \%$, the end of the observation of 4 WAP.

\section{ACKNOWLEDGEMENTS}

The authors thank the Directorate of Research and Community Service at the Directorate General of Strengthening Research and Development, Ministry of Research, Technology, and Higher Education for funding this research in 2018. ; Authors also thank the Laboratory Assistant of Plant Pests and Agronomy as well as the Climatology Laboratory, Faculty of Agriculture, Tanjungpura University, Pontianak, Indonesia and the students who help this research.

\section{REFERENCES}

Amir M, Kardin MK. 1991. Control of fungal diseases. In: Soenarjo E, Damardjati DS, Syam M (eds.). Paddy. Center for Research and Development of Food Crops, Bogor.

Badan Pusat Statistik. 2017. Production, Harvest Area, and Productivity of Rice and Secondary Crops in Indonesia. http://www.pertanian.go.id [2 April 2018].

Department of Agriculture. 2006. Indonesian Rice Directory, Indonesian Center for Rice Research. Subang.

Ilyas S. 2003. Seed coating technology. Pellet Seed Seminar Paper. Ministry of Agriculture \& Faculty of Agriculture, Bogor Agricultural University, Bogor. [Indonesian]

International Rice Research Institute. 1996. Standard Evaluation System for Rice. 4th ed. IRRI, Los Banos, Philippines.

Nortin. 2019. The Influence of seed coating plus biological agents in increasing the growth and yields of rice, which contaminated with pathogen blast. [Thesis]. Faculty of Agriculture, Tanjungpura University, Pontianak. [Indonesian]

Otter W, Bailey DJ, Giligan CA. 2004. Empirical evidence of spatial thresholds to control of fungal parasites and saprotrophs. New Phytol (163): 125-132.

Palupi T, Ilyas S, Machmud M, Widajati E. 2012. Effect of coating formulation on viability, vigor, and storability of rice seeds (Oryza sativa L.). J Agron Indonesia 40 (1):21-28. 
Palupi T, Ilyas S, Machmud M, Widajati E. 2013. Seed coating with biological agents to increase growth and yield. J Agron Indonesia 41 (3): $175-180$.

Sadjad S, Murniati E, Ilyas S. 1999. The Parameter of Seed Vigor Test from Comparative for Simulative. Grasindo, Jakarta. [Indonesian]

Sinaga MS. 2003. The Basics of Plant Disease. Agritext Series, Jakarta [Indonesian]

Sucipto I. 2016. Exploration of endophytic bacteria and fungi as contro agents of blast disease (Pyricularia oryzae) in Lowland Rice. [Thesis]. Graduate School, Bogor Agricultural Institute, Bogor. [Indonesian]

Sudir. 2012. Test the efficacy of Blast 200 SC fungicide against $P$. grisea blast disease through seed treatment and its effect on seed germination as well as rice seedling growth. Research Report Indonesian Center for Rice Research, Sukamandi.
Sudir, Nasution A, Santoso, Nuryanto B. 2014. Pyricularia grisea blast disease in rice plants and its control strategies. Food Crop Sci Tech 9 (2): 85-96.

Suganda T, Yulia E, Widiantini F, Hersanti. 2016. The intensity of blast (Pyricularia oryzae Cav.) in Ciherang rice variety in endemic locations and their effects on loss of results. J Agri 27 (3): 154-159.

Sutopo L. 2002. Seed Technology (Revised Edition). Faculty of Agriculture UNIBRAW. PT Raja Grafindo Persada, Jakarta. [Indonesian]

Yaskur. 2018. Exploration of rice leaf philosophy bacteria as biocontrol agents of pathogenic Pyricularia oryzae, causes of blast disease. [Thesis]. Faculty of Agriculture, Tanjungpura University, Pontianak. [Indonesian] 